\title{
REVIEW
}

\section{Emergency Contraceptives: A Review of Available Options}

\author{
Farhan Khan MSc', Elizabeth Gold MD, MEd, MHSc, FCFP2,3 \\ 'Class of 2016, Faculty of Medicine, Dalhousie University \\ ${ }^{2}$ Faculty of Medicine, Department of Family Medicine, Dalhousie University \\ ${ }^{3}$ Faculty of Medicine, Division of Medical Education, Dalhousie University
}

\begin{abstract}
Emergency contraception is a method of contraception administered after unprotected vaginal intercourse to prevent an unplanned pregnancy. Although, emergency contraceptives (EC) have been around for at least two decades, surveys have shown there are gaps in both health professionals and women's knowledge. Today, there are four main types of EC available: the non-hormonal copper intrauterine device, combined oral estrogen and progestin (Yuzpe regimen), oral progestin-only (levonorgestrel), and oral antiprogestin (ulipristal acetate or mifepristone). This article compares the efficacy, mechanism of action, availability and cost of these methods to help guide health professionals and patients when determining an appropriate EC. Pertinent literature was reviewed, including primary research and guidelines, to provide a current review of options. The copper intrauterine device provides the most effective form of EC and can continually be used as a regular contraceptive. Levonorgestrel (Plan $\left.\mathrm{B}^{\circledR}\right)$ is widely available without a prescription and can be used up to three days after unprotected vaginal intercourse. The Yuzpe regimen is inexpensive, though it is often associated with side effects. Ulipristal acetate and mifepristone are both effective up to five days after unprotected vaginal intercourse; however, mifepristone is currently unavailable in Canada.
\end{abstract}

Emergency contraception has been available for over two decades. Sometimes referred to as the morning after pill, this term is misleading since certain emergency contraceptives (ECs) can be effective for three to even five days after unprotected vaginal intercourse and can take the form of an intrauterine device.

The expanded use of emergency contraception is expected to reduce the number of abortions performed. In Canada, among pregnant women aged 15 to 19 the proportion of abortions is up to $53 \%$, according to 2005 data. ${ }^{1}$ Locally, the Halifax Sexual Health Centre (HSHC) provides over 130 pregnancy options counseling appointments annually. ${ }^{2}$ In 2013, the HSHC provided 124 individuals with emergency contraception. ${ }^{3}$

A study of local family doctors' attitudes and use of emergency contraceptives has found that Nova Scotia family physicians have a generally good knowledge of ECs and do provide them to patients (64\%). ${ }^{4}$ However, family physicians were poorly informed about the length of time that ECs can be effective (only 29\% knew correctly) and many had concerns about the nonprescription availability of ECs. As well, few prescribed ECs in advance for use as a method of prevention in individuals who do not use effective contraception (13\%).

Similarly, Nova Scotia pharmacists are well informed about ECs. Most pharmacists (94\%) have been providing consultations for the EC pill Plan $\mathrm{B}^{\circ}$ since it became available without a prescription in April 2005. ${ }^{5}$ Pharmacists normally spend 6-10 minutes $(48 \%)$ providing Plan $\mathrm{B}^{\circ}$ consultations. However, few pharmacists were knowledgeable about how long after intercourse EC pills are effective (39\%) and few had private areas for counseling about ECs $(46 \%){ }^{5}$

However, Nova Scotia women aged 18 to 51 appear to be poorly informed about ECs with regards to effectiveness, proper timing of administration, how it works, and how to access it. ${ }^{6}$ Women aged 18 to 31 were significantly more likely than women aged 32 to 51 to know that an EC does not always prevent pregnancy ( $83 \%$ vs. $67 \%$ ), that it can be taken more than 12 hours after unprotected vaginal intercourse ( $43 \%$ vs. $26 \%$ ), and that it is available without a prescription in pharmacies ( $45 \%$ vs. $21 \%)$.

By increasing the knowledge of both healthcare providers and individuals about ECs it is hoped that fewer unintended pregnancies will occur. Doing so will reduce the cost, both financial and emotional, of unintended pregnancies and may reduce the number of abortions performed. As new drugs and devices become available it is important that healthcare providers stay up to date about the latest therapies for their patients. 


\section{Methods}

A literature review was conducted using the PubMed database up to September 1, 2014 to identify publications reporting current and emerging emergency contraceptives, using combinations of the search terms: emergency contraception, emergency contraceptive, postcoital methods, contraception, contraceptives, oral contraceptives, and intrauterine contraceptives. Also, the evidence-based clinical resources UpToDate, Dynamed and Cochrane Library were consulted. Additionally, the emergency contraception guidelines from the Society of Obstetricians and Gynaecologists of Canada (September 2012) and the Canadian Paediatric Society (August 2010) were reviewed.

\section{Availability and Uses}

Emergency contraception is a contraceptive method that can be used after unprotected vaginal intercourse, failed contraception or sexual assault to prevent an unwanted pregnancy. Today there are a number of methods available for EC, including the copper intrauterine device and various hormonal methods, with different mechanisms of action, efficacy, and ease of use. Below is an overview of EC methods available. Options for emergency contraception are summarized in Table 1.

\section{Intrauterine Devices}

Copper intrauterine device ( $\mathrm{Cu}$-IUD) is the most effective method for EC and can be continually used for regular contraception, as determined by the
Cochrane Review. ${ }^{8}$ The $\mathrm{Cu}$-IUD maintains efficacy as an EC even with a treatment delay of up to five days after unprotected vaginal intercourse, which is the same timespan that sperm survive in the reproductive tract. ${ }^{9}$ A prospective, multicenter, cohort clinical trial of almost 2000 women requesting EC within 120 hours (five days) of unprotected vaginal intercourse found no pregnancies occurred prior to or at one month after insertion of a Cu-IUD. ${ }^{10}$ Thus, in this study the Cu-IUD is $100 \%$ effective as an EC method. A systematic review of 35 years of research concluded that the Cu-IUD method has a failure rate of $0.09 \%$, superior to all other methods of EC. ${ }^{11}$

The mechanism of action of Cu-IUD is not fully understood. In vitro studies have shown that copper, at concentrations similar to those released from $\mathrm{Cu}$-IUDs, affects the motility, viability, acrosome reaction and fertilizing capacity of human spermatozoa in cervical mucus. ${ }^{12}$ Also, copper increases the smooth muscle activity in the fallopian tube and creates an inflammatory reaction that is toxic for gametes, preventing formation of viable embryos. ${ }^{13,14}$

Insertion of $\mathrm{Cu}$-IUD is the only non-hormonal method of EC available. Cu-IUD for EC has no patient errors and has shown to be well tolerated both in parous and nulliparous women. ${ }^{10}$ As well, once inserted it provides long-acting protection against pregnancy for three to ten years depending on the type. However, $\mathrm{Cu}$-IUDs are seldom used because many women are not aware of its use as an EC and healthcare providers infrequently recommend it. ${ }^{15}$ As well, insertion of a Cu-IUD

\begin{tabular}{|c|c|c|c|}
\hline Method & Dosage & Efficacy $^{7}$ & Cost $^{*}$ \\
\hline $\begin{array}{l}\text { Copper intrauterine device } \\
\text { (Flexi } T^{\circledR} \text { or Nova } \mathrm{T}^{\circledR} \text { ) }\end{array}$ & Single device & $\begin{array}{l}\text { At least } 99 \% \text { of pregnancies } \\
\text { prevented, useful up to five days } \\
\text { postcoitus }\end{array}$ & $\begin{array}{l}\$ 75 \text { (\$88-212 at Shoppers } \\
\text { Drug Mart) }\end{array}$ \\
\hline $\begin{array}{l}\text { Levonorgestrel (Plan } \mathrm{B}^{\circledR} \text {, } \\
\text { NorLevo }{ }^{\circledR} \text {, Next Choice }{ }^{\circledR} \text {, or } \\
\text { Option } 2^{\circledR} \text { ) }\end{array}$ & $\begin{array}{l}0.75 \mathrm{mg} \text { given twice, } 12 \\
\text { hours apart or } 1.5 \mathrm{mg} \text { given } \\
\text { as a single dose }\end{array}$ & $\begin{array}{l}59 \text { to } 94 \% \text {, up to three days } \\
\text { postcoitus }\end{array}$ & $\begin{array}{l}\$ 20 \text { (available off-the- } \\
\text { shelf at pharmacies } \\
\text { without consultation } \\
\text { ranging from } \$ 32 \text { to } \$ 42 \\
\text { at Shoppers Drug Mart) }\end{array}$ \\
\hline $\begin{array}{l}\text { Yuzpe regimen (Estrogen plus } \\
\text { progesterone) }\end{array}$ & $\begin{array}{l}0.1 \text { to } 0.12 \text { mg ethinyl } \\
\text { estradiol plus } 0.5 \text { to } 0.6 \\
\text { mg levonorgestrel in each } \\
\text { dose, given twice, } 12 \text { hours } \\
\text { apart }\end{array}$ & $\begin{array}{l}47-89 \% \text {, up to three days } \\
\text { postcoitus }\end{array}$ & $\begin{array}{l}\$ 5 \text { plus two doses } \\
\text { Gravol }^{\circledR}\end{array}$ \\
\hline Ulipristal acetate & $30 \mathrm{mg}$ single dose & $98-99 \%$, up to five days postcoitus & $\begin{array}{l}\text { Not available as EC in } \\
\text { Canada }\end{array}$ \\
\hline Mifepristone & 10 or $25 \mathrm{mg}$ single dose & $\begin{array}{l}99-100 \% \text {, up to five days } \\
\text { postcoitus }\end{array}$ & $\begin{array}{l}\text { Not available as EC in } \\
\text { Canada }\end{array}$ \\
\hline
\end{tabular}

Table 1. Comparison of emergency contraceptive methods. *Retail price at Halifax Sexual Health Centre, unless otherwise stated. 
requires a trained healthcare professional and should be avoided in women known to have current gonorrhea or chlamydial infection because of the increased risk of pelvic inflammatory disease.$^{16}$ Furthermore, $\mathrm{Cu}$-IUD should be avoided in victims of sexual assault due to the secondary trauma it could cause and their unknown STD status.

\section{Levonorgestrel}

This is a progestin-only method that contains 1.5 $\mathrm{mg}$ of the progestin levonorgestrel, given in a single dose, which is as efficient as the two doses of $0.75 \mathrm{mg}$ given 12 hours apart that was initially described. ${ }^{17}$ Levonorgestrel is approved for use within 72 hours of unprotected vaginal intercourse and is estimated to reduce the risk of pregnancy by 57 to $93 \%$. However, this rate is only for single use. The possibility of failure could increase the more times levonorgestrel is used. Levonorgestrel acts during the pre-ovulatory phase to either delay the process of follicular maturation or to totally arrest follicular development, depending on the time of administration after selection of the dominant follicle. ${ }^{18}$

Levonorgestrel is the most widely available EC in Nova Scotia. ${ }^{19}$ It is available from pharmacies off-theshelf without pharmacist consultation and costs approximately $\$ 20$. It is covered by most public and private insurance plans in Canada.

It is important to note that as of March 2014, Health Canada has asked companies to add new warnings to product packages advising that levonorgestrel is less effective in women weighing 75 to $80 \mathrm{~kg}$ (165-176 lbs), and is not effective in women over $80 \mathrm{~kg}$ (176 $\mathrm{lbs}) .^{20}$ Women who weigh $75 \mathrm{~kg}$ (165 lbs) or more are advised to ask a health professional, such as a doctor or pharmacist, for advice on alternative methods of emergency contraception.

\section{Yuzpe regimen}

First introduced in 1970, the Yuzpe regimen involves a dose of $0.1 \mathrm{mg}$ ethinylestradiol $(4 \times 30 \mu \mathrm{g}$ pills, if $100 \mu \mathrm{g}$ pill unavailable) and $0.5 \mathrm{mg}$ levonorgestrel, given within 72 hours of unprotected vaginal intercourse and repeated after 12 hours. ${ }^{21}$ It is normally prescribed as a higher dose of regular combined oral contraceptive pills, usually four Preven ${ }^{\circ}$ pills. This approximates the dose of levonorgestrel recommended for emergency contraception $(1 \mathrm{mg})$ and works through the same mechanism. However, the combination with ethinylestradiol has more side effects than levonorgestrel alone and hence $\mathrm{Gravol}^{\circ}$ (dimenhydrinate) is typically taken 30 minutes before each dose. This method is less effective and less well tolerated than levonorgestrel (Plan $\mathrm{B}^{\circ}$ ) and is now rarely recommended. ${ }^{22}$ Nevertheless, some women prefer the Yuzpe regimen because it is more accessible and more private than levonorgestrel, which is labelled as an EC.

\section{Ulipristal acetate}

Ulipristal acetate is the newest hormonal EC method. It is sold under the brand-named Ella ${ }^{\circ}$ by Watson Pharmaceuticals in the United States. In Canada ulipristal acetate $\left(\right.$ Fibristal $^{\circ}$ ) is approved for the treatment of fibroids and may be used "off-label" for emergency contraception. Ulipristal acetate is a new class of a second generation selective progesterone receptor modulator and has been approved for use up to five days after sex, similar to the Cu-IUD. It is given as a single dose of $30 \mathrm{mg}$ ulipristal acetate (six x $5 \mathrm{mg}$ tablets).

Ulipristal acetate is thought to work by directly inhibiting follicular rupture. This allows it to be effective even when administered before ovulation when luteinizing hormone has already started to rise, a time when levonorgestrel (Plan $\mathrm{B}^{\circ}$ ) is not effective. When given before the luteinizing hormone surge, ulipristal acetate inhibited $100 \%$ of follicular ruptures. ${ }^{23}$ Administration on the day of the luteinizing hormone peak, ulipristal acetate delayed ovulation for 24-48 hours.

A key concern with the use of ulipristal acetate is that it could alter the effectiveness of progestogencontaining hormonal contraception since ulipristal acetate is a selective progesterone receptor modulator. This question has not been studied. In the absence of evidence, the drug manufacturer advises concomitant use of hormonal contraception with a reliable barrier method until next menses. ${ }^{24}$

\section{Mifepristone}

The results of the quality assessment are presented in Mifepristone is commonly used as an abortifacient or abortion pill in 200 or $600 \mathrm{mg}$ doses. However in low doses, 10 or $25 \mathrm{mg}$, mifespristone can be used as an EC within five days (120 hours) of unprotected vaginal intercourse. ${ }^{17}$ At low doses, mifepristone acts by delaying or inhibiting ovulation when it is administered during the follicular phase. ${ }^{18}$ However, its use as an EC is limited and is not approved in the United States and Canada. 


\section{Special considerations}

\section{Pregnancy and breastfeeding}

No association has been found between the exposure to levonorgestrel after failed EC use and the risk of major congenital malformation, pregnancy complications or any other adverse pregnancy outcomes. ${ }^{25}$ Exposure to mifepristone, in high doses, has not been associated with teratogenicity. ${ }^{26}$ The effect of ulipristal acetate on pregnancies is still being investigated and is currently unknown.

Breastfeeding after taking levonorgestrel should be avoided for at least eight hours due to high concentration of levonorgestrel in breast milk. ${ }^{27}$ After 24 hours levonorgestrel cannot be detected. The concentration of mifepristone in breast milk is low following high dose treatment and breastfeeding is not contraindicated. ${ }^{28}$ Ulipristal acetate has not been studied in breastfeeding women, but since ulipristal acetate is a lipophilic compound, it is theoretically possible for ulipristal acetate to cross into breast milk. Therefore, it is recommended that breastfeeding women who take ulipristal acetate should avoid breastfeeding for 36 hours following treatment. ${ }^{29}$

\section{Effect of BMI on EC efficacy}

Glasier et al found that the risk for pregnancy was more than three times greater for women with BMI 30 and above, compared with women with BMI under 25 with any EC method. ${ }^{30}$ The effect of BMI on pregnancy rate was greater in women treated with levonorgestrel than ulipristal acetate. The limit of efficacy was reached at $70 \mathrm{~kg}$ (155 lbs) for levonorgestrel compared with $88 \mathrm{~kg}$ (194 lbs) in women having taken ulipristal acetate.

\section{Conclusions}

There are a number of emergency contraception methods available. The one used by a woman will depend on her individual needs and ease of availability. The Cu-IUD provides the most effective EC method for up to five days after sex with the additional benefit of being a highly effective continuous regular contraceptive method. Levonorgestrel is the most widely available and used EC in Nova Scotia. However, levonorgestrel's activity wanes over time and should be used as soon as possible, within 72 hours after sex. The most recently developed EC ulipristal acetate provides excellent protection for up to five days after sex, but its use is off-label in Canada. In the United States it has limited prescription-only availability and is often more expensive. Thus, as new forms of EC come on the market, healthcare providers and women will be able to choose the best suited EC for individual patients.

\section{Acknowledgements}

We would like to thank John Britton, Executive Director of Halifax Sexual Health Centre (HSHC) for providing us with clinic statistics and for providing suggestions on the manuscript. The $\mathrm{HSHC}$ is a non-for-profit organization that is committed to providing inclusive, respectful sexual health and wellness services at their clinic and through educational outreach.

\section{References}

1. Statistics Canada. "Table 106-9002 - Pregnancy outcomes, by age group, Canada, provinces and territories, annual." CANSIM database. 2008 < http://www5.statcan.gc.ca/cansim/a26?lang=e ng\&retrLang=eng\&id=1069002\&pattern=\&csid $>($ December 31 , 2014).

2. Halifax Sexual Health Centre. "HSHC Stats." $2011<$ http://www. hshc.ca/index.php?q=content/hshc-stats $>$ (August 17, 2014).

3. Britton, John Executive Director, Halifax Sexual Health Centre. August 11, 2014; e-mail.

4. Langille D, Allen M, Whelan A. Emergency contraception: knowledge and attitudes of Nova Scotian family physicians. Canadian Fam Physician 2012;58(5):548-554.

5. Whelan A, Langille D, Hurst E. Nova Scotia pharmacists' knowledge of, experiences with and perception of factors interfering with their ability to provide emergency contraceptive pill consultations. Int J Pharm Pract 2013;21(5):314-321. http:// dx.doi.org/10.1111/ijpp.12017

6. Whelan A, Langille D, White SJK, Asbridge M, Flowerdew G. Knowledge of, beliefs about, and perceived barriers to the use of the emergency contraception pill among women aged 18-51 in Nova Scotia. Pharm Pract 2011;9(3):148-155.

7. Zieman M. "Emergency contraception." $2014<$ http://www. uptodate.com/contents/emergency-contraception> (August 17, 2014).

8. Cheng L, Che Y, Gülmezoglu AM. Interventions for emergency contraception. Cochrane Database Syst Rev 2012;8:CD001324. http://dx.doi.org/10.1002/14651858.CD001324.pub4

9. Zhou L, Xiao B. Emergency contraception with Multiload Cu-375 SL IUD: a multicenter clinical trial. Contraception 2001;64(2):107112.

10. Wu S, Godfrey EM, Wojdyla D, Dong J, Cong J, Wang C, et al. Copper T380A intrauterine device for emergency contraception: a prospective, multicentre, cohort clinical trial. BJOG 2010;117(10):1205-1210. http://dx.doi.org/10.1111/j.14710528.2010.02652.x

11. Cleland K, Zhu H, Goldstuck N, Cheng L, Trussell J. The efficacy of intrauterine devices for emergency contraception: a systematic review of 35 years of experience. Hum Reprod 2012;27(7):19942000. http://dx.doi.org/10.1093/humrep/des140

12. Ullmann G, Hammerstein J. Inhibition of sperm motility in vitro by copper wire. Contraception 1972;6(1):71-76. http://dx.doi. org/10.1016/S0010-7824(72)80007-6

13. Larsson B, Ljung B, Hamberger L. The influence of copper on the in vitro motility of the human fallopian tube. Am J Obstet Gynecol 1976;125(5):682-690.

14. Hagenfeldt K, Johannisson E, Brenner P. Intrauterine contraception with the copper-T device. 3. Effect upon endometrial morphology. Contraception 1972;6(3):207-218.

15. Wright R, Frost C, Turok D. A qualitative exploration of emergency contraception users' willingness to select the copper 
IUD. Contraception 2012;85(1):32-35. http://dx.doi.org/10.1016/j. contraception.2011.04.005

16. Harper C, Speidel JJ, Drey E, Trussell J, Blum M, Darney P. Copper intrauterine device for emergency contraception: clinical practice among contraceptive providers. Obstet Gynecol 2012;119(2):220226. http://dx.doi.org/10.1097/AOG.0b013e3182429e0d

17. von Hertzen H, Piaggio G, Ding J, Chen J, Song S, Baartfai G, et al. Low dose mifepristone and two regimens of levonorgestrel for emergency contraception: a WHO multicentre randomised trial. Lancet 2002;360(9348):1803-1810. http://dx.doi.org/10.1016/ S0140-6736(02)11767-3

18. Marions L, Cekan S, Bygdeman M, Gemzell Danielsson K. Effect of emergency contraception with levonorgestrel or mifepristone on ovarian function. Contraception 2004;69(5):373-377. http:// dx.doi.org/10.1016/j.contraception.2003.11.018

19. NS HealthLink 811. "Plan B Emergency Contraception." 2014 <http://nshealthlink811.ca/documents/English\%20-\%20 Health\%20Information/Emergency\%20Contraception\%20HIT. pdf $>$ (August 17, 2014).

20. Health Canada. "Emergency contraceptive pills to carry warnings for reduced effectiveness in women over a certain body weight." $2014<\mathrm{http} / /$ healthycanadians.gc.ca/recall-alert-rappel-avis/hcsc/2014/38701a-eng.php> (August 17, 2014).

21. Yuzpe AA, Lancee WJ. Ethinylestradiol and dl-norgestrel as a postcoital contraceptive. Fertil Steril 1977;28(9):932-936.

22. Randomised controlled trial of levonorgestrel versus the Yuzpe regimen of combined oral contraceptives for emergency contraception. Task Force on Postovulatory Methods of Fertility Regulation. Lancet 1998;352(9126):428-433.

23. Brache V, Cochon L, Jesam C, Maldonado R, Salvatierra AM, Levy DP, et al. Immediate pre-ovulatory administration of 30 mg ulipristal acetate significantly delays follicular rupture. Hum Reprod 2010;25(9):2256-2263. http://dx.doi.org/10.1093/ humrep/deq157

24. Salcedo J, Rodriguez M, Curtis K, Kapp N. When can a woman resume or initiate contraception after taking emergency contraceptive pills? a systematic review. Contraception 2013;87(5):602-604. http://dx.doi.org/10.1016/j. contraception.2012.08.013

25. Meng C, Marions L, Bystrom B, Gemzell Danielsson K. Effects of oral and vaginal administration of levonorgestrel emergency contraception on markers of endometrial receptivity. Hum Reprod 2010;25(4):874-883. http://dx.doi.org/10.1093/humrep/ deq007

26. Wolf JP, Chillik CF, Dubois C, Ulmann A, Baulieu EE, Hodgen GD. Tolerance of perinidatory primate embryos to RU 486 exposure in vitro and in vivo. Contraception 1990;41(1):85-92.

27. Gainer E, Massai R, Lillo S, Reyes V, Forcelledo ML, Caviedes $\mathrm{R}$, et al. Levonorgestrel pharmacokinetics in plasma and milk of lactating women who take $1.5 \mathrm{mg}$ for emergency contraception. Hum Reprod 2007;22(6):1578-1584. http://dx.doi.org/10.1093/ humrep/dem034

28. Saav I, Fiala C, Hamalainen J, Heikinheimo O, Gemzell Danielsson K. Medical abortion in lactating women-low levels of mifepristone in breast milk. Acta Obstet Gynecol Scand 2010;89(5):618-622.

29. Gemzell-Danielsson K, Meng CX. Emergency contraception: potential role of ulipristal acetate. Int J Womens Health 2010;2:5361.

30. Glasier A, Cameron S, Blithe D, Scherrer B, Mathe H, Levy D, et al. Can we identify women at risk of pregnancy despite using emergency contraception? data from randomized trials of ulipristal acetate and levonorgestrel. Contraception 2011;84(4):363-367. http://dx.doi.org/10.1016/j.contraception.2011.02.009

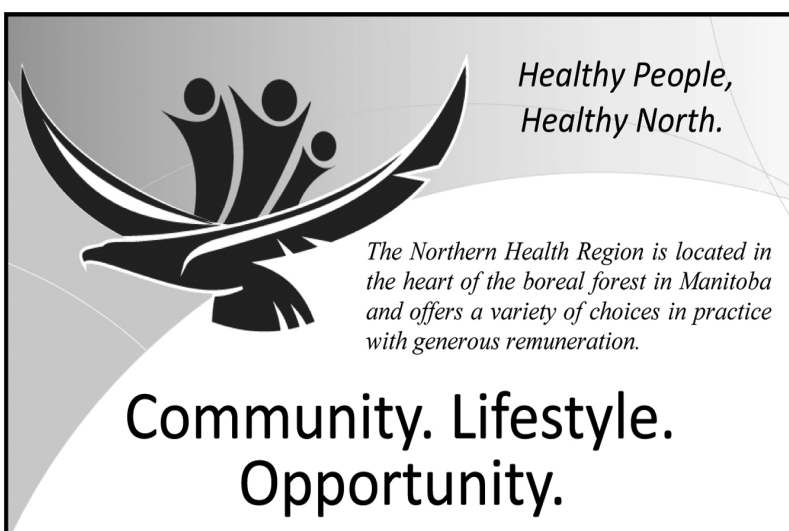

The Northern Health Region would like you to find a healthy work-life balance in one of our communities working in a multidisciplinary environment with the ability to choose a practice model which suits both your personal and professional needs.

We are an employer of choice who are seeking both full/part-time Family Physicians, Specialists and locums to join our team!

For more information about exciting opportunities in the Northern Health Region, please contact:

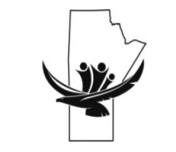

Marie MacPhail, Recruiter

\section{physicianrecruiter@nrha.ca}

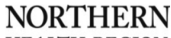

www.northernhealthregion.ca

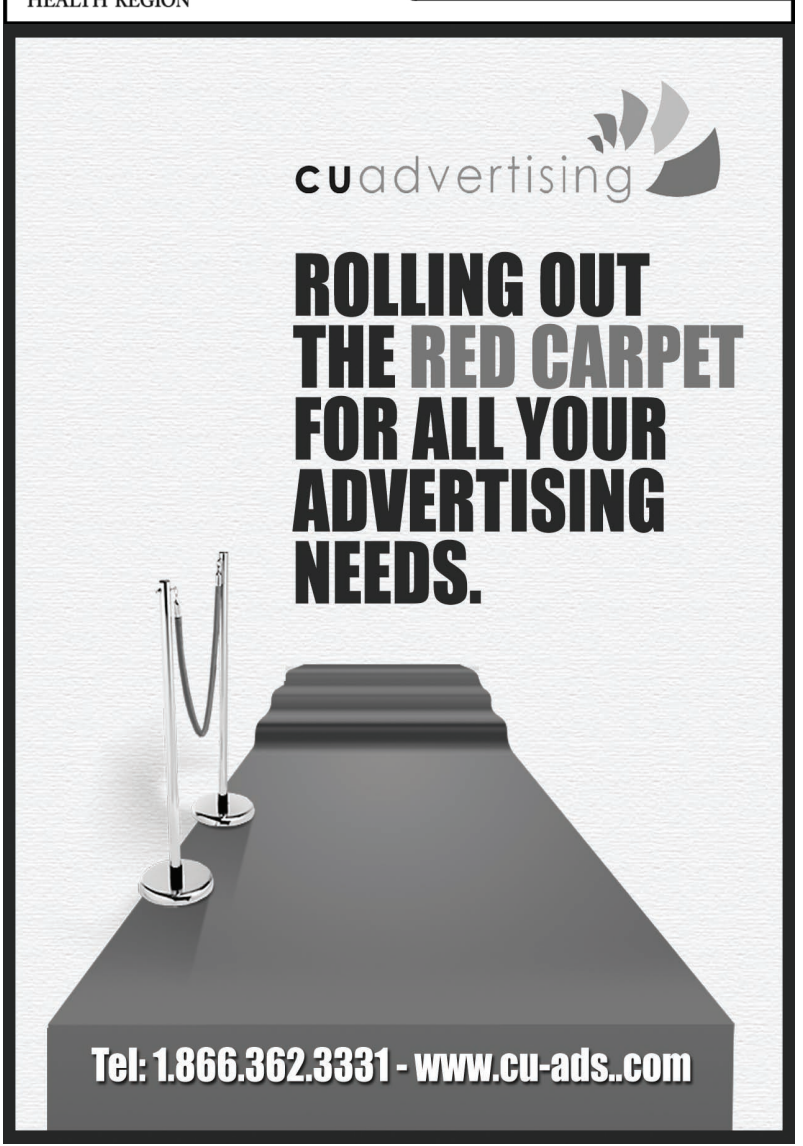

